\title{
Pulmonary embolism: new treatments for an old problem
}

This article was published in the following Dove Press journal:

Open Access Emergency Medicine

31 October 2016

Number of times this article has been viewed

John Ryan

Emergency Department, St Vincent's University Hospital, Dublin, Ireland

Correspondence: John Ryan Emergency Department, St Vincent's University Hospital, Elm Park, Merrion Road, Dublin 4, Ireland

$\mathrm{Tel}+353$ । 22। 3815

Fax +353 । 22। 4908

Email J.Ryan@svuh.ie
Abstract: Nonvitamin K antagonist oral anticoagulants, previously referred to as novel oral anticoagulants, have emerged in recent years as attractive treatment options for acute pulmonary embolism (PE). However, despite the widespread anticipation by physicians and the approval of rivaroxaban, apixaban, dabigatran, and more recently edoxaban, there is still some reluctance to choose these newer agents over conventional treatment with heparin/vitamin $\mathrm{K}$ antagonists. Acute PE puts a considerable strain on emergency departments, and medical staff rely on efficient diagnosis and risk assessment to manage the condition appropriately and economically. Rivaroxaban and apixaban offer a convenient and cost-effective single-drug therapeutic approach. The ease of administration and drug management may enable earlier discharge and outpatient treatment in low-risk patients and alleviate the demands put on emergency-care infrastructures. This review discusses the current guidelines and anticoagulation options in the emergency setting for patients with acute PE and explores the reasons for the slow transition from old to new treatment options.

Keywords: deep vein thrombosis, non-VKA oral anticoagulant, pulmonary embolism, treatment

\section{Introduction}

Acute pulmonary embolism (PE) is a potentially life-threatening medical emergency that requires urgent intervention. ${ }^{1}$ Patients with $\mathrm{PE}$ have a case fatality rate of $7 \%-11 \%,{ }^{2}$ a fact that must be borne in mind by the health care professionals involved at all stages of patient care, including the primary care practitioner, emergency physician, and continuing care doctor. Health care providers should be aware that their patient is at risk of $\mathrm{PE}$ and should take the appropriate steps in delivering preventive and therapeutic care.

In most cases, PE is a consequence of a deep vein thrombosis (DVT). It has been shown that $>80 \%$ of patients with proven $\mathrm{PE}$ have a residual $\mathrm{DVT}^{3}$ and $>50 \%$ have an acute proximal DVT associated with PE. ${ }^{4}$ Acute treatment of venous thromboembolism (VTE; comprising DVT and PE) and its secondary prevention are traditionally based on parenteral heparin overlapping with and followed by an oral vitamin $\mathrm{K}$ antagonist (VKA)..$^{5-8}$

Nonvitamin K antagonist oral anticoagulants (NOACs), including rivaroxaban, apixaban, dabigatran, and edoxaban, have been introduced to the anticoagulation landscape over the past decade. They offer attractive alternatives to, and were developed to overcome limitations associated with, heparin/VKAs. ${ }^{9,10}$ The NOACs are characterized by convenient oral administration, fixed dosing regimens, a fast onset of action, minimal drug-drug interactions, no dietary restrictions, and no requirement 
for routine coagulation monitoring. In addition, unlike heparin, NOAC use is not associated with the development of thrombocytopenia. ${ }^{11}$

The purpose of this review is to assess NOAC use in the treatment of patients with acute PE in the emergency department (ED) setting. The use of rivaroxaban and apixaban in a single-drug approach for the treatment of acute PE is highlighted and compared with the dual-drug approach of dabigatran and a parenteral agent. Risk assessment and diagnostic approaches, current guidelines, and relevant clinical study data are discussed, in addition to the pros and cons of the available anticoagulants and possible reasons for a slower-than-expected transition from conventional to newer therapies.

\section{Methods}

The current European and North American guidelines for the treatment of VTE were reviewed, including those of the European Society of Cardiology (ESC), ${ }^{12}$ National Institute for Health and Care Excellence, ${ }^{13-16}$ American College of Chest Physicians (ACCP), ${ }^{8}$ and Summary of Product Characteristics for each NOAC, ${ }^{17-20}$ in addition to all relevant published randomized Phase III clinical studies of the NOACs. ${ }^{21-25}$ Other references were sourced via PubMed searches using the search string (oral anticoagulant AND pulmonary embolism AND [emergency OR acute medicine OR ambulatory]). The results were filtered to ensure that only references from the past 10 years were included and were further refined by a manual review of each abstract.

\section{Setting the scene}

A 28-year-old woman presents to the ED. She complains of pleuritic left-sided chest pain for the past 24 hours that is getting worse. There is an associated shortness of breath. She sustained an undisplaced fracture of her distal fibula in a hockey match 3 weeks before the onset of symptoms, for which she has been placed in a below-knee plaster cast. She has been nonweight bearing. Her physical examination is normal except for a relative tachycardia at 88 beats $/ \mathrm{min}$. Her only medication is the oral contraceptive pill. She smokes ten cigarettes per day. She lives with her mother who has mild dementia. Her electrocardiograph and chest X-ray are unremarkable, and no evidence of right ventricular dysfunction or myocardial damage is found in the corresponding test. The patient's history establishes no evidence of an inherited blood clotting disorder; therefore, no genetic analysis is conducted to assess for Factor V Leiden thrombophilia and/or prothrombin G20210A. Blood tests are normal except for an elevated d-dimer ( $1.1 \mu \mathrm{g} / \mathrm{mL}$ fibrinogen-equivalent units). A computed tomography pulmonary angiogram shows bilateral PE, and a Doppler ultrasound of her lower limb shows a clot extending to just above the popliteal vein of the injured leg. Traditional care includes a package of low molecular weight heparin (LMWH), an oral VKA, and a hospital admission of up to 5 days until her anticoagulation is regulated. A junior doctor suggests outpatient treatment with a NOAC. You know this would suit the patient because of her domestic responsibilities in caring for her mother, and it would also be in line with hospital protocols, but you have not treated someone as an outpatient before. Is it really cost-effective? Is it safe? What about the lack of reversibility? Is it time for a change from conventional treatment to new options? What advice does she need about returning to contact sports?

\section{Risk assessment of PE}

Adequate risk stratification is important to prevent PE-related morbidity and mortality as well as unnecessary treatment. All patients with PE require rapid risk stratification, according to the expected PE-related risk of early death, to guide the ED physician on the most appropriate intervention strategy. The Pulmonary Embolism Severity Index (PESI) and the simplified PESI (sPESI) are established assessment tools. ${ }^{8,12,26,27}$ The negative predictive value of the SPESI score has shown its utility in a post hoc analysis of the EINSTEIN PE study data. Of the 4,831 patients classified using sPESI, $9.7 \%$ had a score of $\geq 2$, whereas $53.6 \%$ and $36.7 \%$ had scores of 0 and 1 , respectively. Patients with an sPESI score of $\geq 2$ demonstrated a higher rate of all-cause mortality and adverse events within the first 30 days. $^{28}$

\section{Returning to our case}

According to the sPESI criteria, this patient is likely to be considered to be at low risk ( $\leq 80$ years of age, no known cancer, no chronic heart failure or pulmonary disease, pulse rate $<110$ beats $/ \mathrm{min}$, systolic blood pressure $\geq 100 \mathrm{mmHg}$, arterial oxyhemoglobin saturation $\geq 90 \%$ ). ${ }^{12}$

\section{Guidelines on the emergency treatment of acute PE}

The 2014 ESC guidelines for the diagnosis and management of acute PE discuss risk-adjusted strategies for PE management. ${ }^{12}$

The ESC suggests that parenteral anticoagulation should be initiated while awaiting the results of diagnostic tests in patients with high or intermediate clinical probability of PE, such as the patient case presented in this article. Parenteral 
anticoagulants, including intravenous unfractionated heparin (UFH), subcutaneous LMWH, or subcutaneous fondaparinux, can induce an immediate state of anticoagulation. ${ }^{12}$ Owing to their relatively lower risk for major bleeding and heparininduced thrombocytopenia, LMWH or fondaparinux is preferred over UFH for initial anticoagulation in PE. However, a short half-life, ease of effect monitoring, and rapid reversal by protamine render UFH the preferred parenteral anticoagulant in patients with severe renal impairment (creatinine clearance $[\mathrm{CrCl}]<30 \mathrm{~mL} / \mathrm{min}$ ) or severe obesity, or in those who may undergo reperfusion. ${ }^{12}$

For patients with high-risk $\mathrm{PE}$ and shock or hypotension, the ESC guidelines recommend that intravenous anticoagulation with UFH be initiated without delay and thrombolytic therapy be initiated unless contraindicated or failed, in which case surgical pulmonary embolectomy or, alternatively, percutaneous catheter-directed treatment should be conducted. ${ }^{12}$

For patients with intermediate- or low-risk PE without shock or hypotension, the ESC guidelines recommend anticoagulant treatment based around a parenteral treatment followed by a VKA, with NOACs as an alternative option. The recommended dosing regimens for the different NOACs are as follows: rivaroxaban $15 \mathrm{mg}$ twice daily for 21 days followed by $20 \mathrm{mg}$ once daily, apixaban $10 \mathrm{mg}$ twice daily for 7 days followed by $5 \mathrm{mg}$ twice daily, dabigatran acute-phase parenteral anticoagulation for 7 days followed by $150 \mathrm{mg}$ twice daily (or $110 \mathrm{mg}$ twice daily for patients $\geq 80$ years of age or under concomitant verapamil treatment), and edoxaban acute-phase parenteral anticoagulation for $\geq 5$ days followed by $60 \mathrm{mg}$ once daily. In the emergency setting, patients with PE may have received initial therapy with heparins; however, switching to NOACs is straightforward. Rivaroxaban, apixaban, dabigatran, and edoxaban can be started around the time of the next scheduled administration of the parenteral anticoagulant. For continuously administered parenteral products, rivaroxaban and dabigatran should be administered at the time of discontinuation of the parenteral agent (there is no specification available for apixaban). ${ }^{17-20}$ According to the relevant Summary of Product Characteristics, rivaroxaban, apixaban, and edoxaban are not recommended for patients with $\mathrm{CrCl}<15 \mathrm{~mL} / \mathrm{min}$ and dabigatran is contraindicated in patients with $\mathrm{CrCl}$ $<30 \mathrm{~mL} / \mathrm{min}$ (Table 1). ${ }^{17-20}$ Contraindications common for rivaroxaban, apixaban, dabigatran, and edoxaban are listed in Table 1.

The choice of whether to use a VKA or NOAC is based on many factors, including the clinical profile of a patient (eg, a
VKA might be the best option for patients with $\mathrm{CrCl}<15 \mathrm{~mL}$ / $\mathrm{min}$ ), practical aspects (fixed drug regimen of NOACs vs routine anticoagulation monitoring and dose adjustment for VKAs), and patient satisfaction (eg, improved length of hospital stay for patients hospitalized for VTE taking NOACs vs enoxaparin/ VKA). ${ }^{29-31}$ All NOACs have been demonstrated to be costeffective options for the treatment of patients with acute PE. ${ }^{13-16}$

\section{Returning to our case}

The clinical profile of the patient described in the case scenario allows for treatment with a VKA or any of the NOACs, and therefore, personal preferences would have to be explored. The benefits of not having to return to an anticoagulation monitoring service with NOACs may suit this patient's domestic situation. The discussion may further include education on the generic risks of anticoagulation and the importance of checking comprehension before discharge.

The ESC further recommends that patients at a low risk of mortality according to PESI (and sPESI) score be considered for early discharge and continuation of treatment at home, assuming proper outpatient care and anticoagulant treatment can be provided. ${ }^{12}$ The ACCP states that at-home treatment of acute PE, either without hospital admission via discharge from the ED or with admission and early discharge, is feasible with LMWH. ${ }^{8}$ However, further trials are necessary to define the criteria that allow early discharge and home treatment in such low-risk patients. A recent post hoc analysis of EINSTEIN PE data stratifying clinical outcomes by sPESI scores supported the use of sPESI to identify lowrisk patients. Rivaroxaban demonstrated equally effective treatment to standard therapy for low- and high-risk patients with a potentially better safety profile. Offering rivaroxaban from the beginning of treatment instead of a parenteral agent could simplify hospital-to-home transition. ${ }^{28}$

For most cases of suspected acute PE without hemodynamic compromise, initiation of parenteral anticoagulation is recommended without delay. LMWH or fondaparinux, given subcutaneously at weight-adjusted doses without monitoring, is the treatment of choice unless there is severe renal dysfunction. ${ }^{12}$ Caution is also required when administering anticoagulant therapy to pregnant or elderly patients and to children. ${ }^{8,12,32}$

The 2016 ACCP guidelines recommend rivaroxaban as an alternative treatment option to initial parenteral anticoagulation for the treatment of acute PE. Furthermore, LMWH or fondaparinux is recommended over intravenous UFH or subcutaneous UFH. ${ }^{8}$ 
Table I Contraindications to NOACs as defined by the European SPC

\begin{tabular}{|c|c|c|c|c|}
\hline & Rivaroxaban & Apixaban & Dabigatran & Edoxaban \\
\hline $\begin{array}{l}\text { Comedication with strong P-gP } \\
\text { inhibitors }\end{array}$ & & & $\begin{array}{l}\text { Contraindicated in } \\
\text { patients receiving } \\
\text { systemic ketoconazole, } \\
\text { ciclosporin, itraconazole, } \\
\text { or dronedarone }\end{array}$ & \\
\hline $\begin{array}{l}\text { Comedication with CYP3A4 } \\
\text { and P-gP inducers }\end{array}$ & & $\begin{array}{l}\text { Contraindicated in patients } \\
\text { receiving rifampicin, } \\
\text { phenytoin, carbamazepine, } \\
\text { phenobarbital, or St John's } \\
\text { wort }\end{array}$ & & \\
\hline $\begin{array}{l}\text { Comedication with other } \\
\text { anticoagulants }\end{array}$ & $\begin{array}{l}\text { Contraindicated } \\
\text { except under specific } \\
\text { circumstances of switching } \\
\text { anticoagulant therapy } \\
\text { or when UFH is given } \\
\text { at doses necessary to } \\
\text { maintain an open central } \\
\text { venous or arterial catheter }\end{array}$ & $\begin{array}{l}\text { Contraindicated } \\
\text { except under specific } \\
\text { circumstances of switching } \\
\text { anticoagulant therapy or } \\
\text { when UFH is given at doses } \\
\text { necessary to maintain an } \\
\text { open central venous or } \\
\text { arterial catheter }\end{array}$ & $\begin{array}{l}\text { Contraindicated } \\
\text { except under specific } \\
\text { circumstances of switching } \\
\text { anticoagulant therapy or } \\
\text { when UFH is given at doses } \\
\text { necessary to maintain an } \\
\text { open central venous or } \\
\text { arterial catheter }\end{array}$ & $\begin{array}{l}\text { Contraindicated } \\
\text { except under specific } \\
\text { circumstances of switching } \\
\text { anticoagulant therapy } \\
\text { or when UFH is given } \\
\text { at doses necessary to } \\
\text { maintain an open central } \\
\text { venous or arterial catheter }\end{array}$ \\
\hline $\begin{array}{l}\text { Hypersensitivity to active } \\
\text { substance or excipient }\end{array}$ & $\begin{array}{l}\text { Contraindicated (refer } \\
\text { SPC for a detailed list of } \\
\text { compounds) }\end{array}$ & $\begin{array}{l}\text { Contraindicated (refer } \\
\text { SPC for a detailed list of } \\
\text { compounds) }\end{array}$ & $\begin{array}{l}\text { Contraindicated (refer } \\
\text { SPC for a detailed list of } \\
\text { compounds) }\end{array}$ & $\begin{array}{l}\text { Contraindicated (refer } \\
\text { SPC for a detailed list of } \\
\text { compounds) }\end{array}$ \\
\hline $\begin{array}{l}\text { Active clinically significant } \\
\text { bleeding, lesion, or condition, } \\
\text { if considered to be a significant } \\
\text { risk for major bleeding }\end{array}$ & Contraindicated & Contraindicated & Contraindicated & Contraindicated \\
\hline $\begin{array}{l}\text { Severe renal impairment }(\mathrm{CrCl} \\
<30 \mathrm{~mL} / \mathrm{min})\end{array}$ & & & Contraindicated & \\
\hline Renal failure $(\mathrm{CrCl}<15 \mathrm{~mL} / \mathrm{min})$ & Contraindicated & Contraindicated & Contraindicated & Contraindicated \\
\hline $\begin{array}{l}\text { Concomitant treatment of ACS } \\
\text { with antiplatelet therapy in } \\
\text { patients with a prior stroke or } \\
\text { a TIA }\end{array}$ & Contraindicated & & & \\
\hline Hepatic disease & $\begin{array}{l}\text { Contraindicated } \\
\text { when associated with } \\
\text { coagulopathy and clinically } \\
\text { relevant bleeding risk }\end{array}$ & $\begin{array}{l}\text { Contraindicated } \\
\text { when associated with } \\
\text { coagulopathy and clinically } \\
\text { relevant bleeding risk }\end{array}$ & $\begin{array}{l}\text { Contraindicated when } \\
\text { expected to have any } \\
\text { impact on survival }\end{array}$ & $\begin{array}{l}\text { Contraindicated } \\
\text { when associated with } \\
\text { coagulopathy and clinically } \\
\text { relevant bleeding risk }\end{array}$ \\
\hline Pregnancy and breastfeeding & Contraindicated & & & Contraindicated \\
\hline NOAC-specific contraindications & & & $\begin{array}{l}\text { Prosthetic heart valves } \\
\text { requiring anticoagulant } \\
\text { treatment }\end{array}$ & $\begin{array}{l}\text { Uncontrolled severe } \\
\text { hypertension }\end{array}$ \\
\hline
\end{tabular}

Abbreviations: ACS, acute coronary syndrome; $\mathrm{CrCl}$, creatinine clearance; CYP3A4, cytochrome P450 3A4; min, minute; NOAC, nonvitamin $\mathrm{K}$ antagonist oral anticoagulant; P-gp, P-glycoprotein; SPC, Summary of Product Characteristics; TIA, transient ischemic attack; UFH, unfractionated heparin.

Anticoagulant treatment in patients with PE is intended to prevent the recurrence of VTE. There is a general consensus that treatment should last for at least 3 months. The decision on whether and how long to maintain therapy beyond this period is based on a more comprehensive patient assessment. $^{8,12}$

The ESC guidelines recommend VKA-based treatment for 3 months in patients with provoked PE. The guidelines also state that NOACs should be considered as an alternative to a VKA (except for patients with severe renal impairment) if extended anticoagulation treatment is necessary. The assessment of patients with unprovoked PE identifies patients at a higher long-term relative risk of recurrence, based on the number of previous venous thromboembolic events experienced, and the presence of antiphospholipid antibody syndrome, hereditary thrombophilia, and residual thrombosis in the proximal veins. Patients with unprovoked PE should be treated with a VKA for at least 3 months. Indefinite anticoagulation treatment should be considered for patients with a first unprovoked proximal DVT or PE and a low risk of bleeding. ${ }^{12}$ 
The ACCP recommends a treatment period of 3 months for PE that is provoked by surgery or by a nonsurgical transient risk factor. For a first PE that is unprovoked, extended therapy is suggested if the bleeding risk is low or moderate; 3 months' therapy is recommended if the bleeding risk is high. If the first PE is associated with active cancer, extended therapy is recommended and LMWH is suggested over a VKA. Both VKAs and LMWH are recommended over rivaroxaban or dabigatran..$^{8,33}$

\section{Management of bleeding and laboratory testing of NOACs}

All anticoagulants carry a risk of bleeding, and management of bleeding events is broadly similar regardless of anticoagulant used.

In patients with normal renal function, surgical procedures with standard bleeding risk should be delayed for 24 hours. In patients with impaired renal function and/or procedures with a high risk of bleeding, a delay of 2-6 days should be considered, depending on which NOAC is used. ${ }^{34}$

In the case of life-threatening bleeding, administration of hemostatic procoagulant agents - prothrombin complex concentrate, activated prothrombin complex concentrate, or recombinant activated Factor VII - may be considered. ${ }^{35}$ In addition, absorption of dabigatran can be reduced by administering activated charcoal shortly after ingestion, or it can be removed from the blood via hemodialysis. ${ }^{36}$ Idarucizumab - the first clinically (US Food and Drug Administration) approved reversal agent for a NOAC - is an antibody fragment that inactivates the dabigatran molecule by binding to its thrombin-binding site and is given intravenously as a one-off dose. ${ }^{36,37}$ Other reversal agents are currently in premarketing clinical studies and claim to offer effective reversal of Factor X inhibitors (andexanet) and NOACs in general (PER977). ${ }^{36,37}$ Andexanet alfa binds the Factor Xa inhibitors as well as heparin-activated antithrombin, thereby inactivating the anticoagulant. It could potentially act as a reversal agent for all anti-Factor Xa NOACs, heparin, and fondaparinux. A Phase II study in healthy volunteers has demonstrated improved laboratory parameters. ${ }^{36,38}$ PER977 has been developed as a reversal agent for heparin and fondaparinux, but has also shown activity against the NOACs, including dabigatran. ${ }^{36}$

Available real-world evidence on bleeding events after NOAC treatment indicates that rivaroxaban-related bleeding may be lower than or similar to bleeding after VKA treatment. ${ }^{39,40}$ The recently completed XALIA study, for example, has assessed the safety and effectiveness of rivaroxaban for the treatment and secondary prevention of VTE. A numerically lower proportion of major bleeding events were demonstrated for rivaroxaban versus standard of care ( $0.8 \% \mathrm{vs} 2.1 \%)$ in the propensity score-adjusted population. ${ }^{40}$ Further data from studies evaluating the safety of NOACs are highly anticipated.

NOACs do not require routine coagulation monitoring. However, a rapid assessment of the patient's coagulation status may be helpful in emergency situations, such as hemorrhage or overdose, and before urgent surgery. Tests are available that can be used to measure the plasma levels of NOACs or their anticoagulant activity. The thrombin clotting time assay can be used to measure dabigatran, whereas anti-Factor Xa assays can measure the plasma concentrations of rivaroxaban and apixaban. The prothrombin time assay (when used with a sensitive reagent) may indicate the presence or absence of a clinically relevant anticoagulant effect of rivaroxaban, but international normalized ratio must not be used. ${ }^{34,41}$ When interpreting test results, blood sampling time in relation to tablet intake must be considered. ${ }^{42}$

It is important to educate patients discharged from the ED on NOAC therapy, the generic bleeding risks of anticoagulation, the options for bleeding management, and the need for caution when participating in activities where falls or a direct trauma is a possibility.

\section{What the evidence tells us: Phase III clinical studies for the treatment of acute PE}

There are a few Phase III clinical studies that have assessed anticoagulants in a PE-specific population. Matisse-PE and EINSTEIN PE are the two most recent studies in this area. The Matisse-PE study assessed fondaparinux versus UFH for the 3-month incidence of the composite end point of symptomatic, recurrent PE (nonfatal and fatal) and new or recurrent DVT, ${ }^{43}$ whereas EINSTEIN PE assessed rivaroxaban for a period of 3-12 months. ${ }^{21}$

In the open-label Matisse-PE study, a total of 2,213 patients were randomized to receive either fondaparinux or UFH. ${ }^{43}$ In both groups, treatment was transitioned to a VKA for 3 months. Fondaparinux was noninferior to UFH for the primary efficacy end point (3.8\% vs $5.0 \%$; $95 \%$ confidence interval $[\mathrm{CI}]-3.0-0.5) .{ }^{43}$ Both treatment groups had a similar incidence of principal safety outcome events, namely, major bleeding during the initial treatment period $(1.3 \%$ vs $1.1 \%$; $95 \% \mathrm{CI}-0.7-1.1)$ and death during the 3-month study period (5.2\% vs $4.4 \%$; $95 \%$ CI $-1.0-2.6) .{ }^{43}$

EINSTEIN PE was an open-label study of 4,832 patients with PE, with or without DVT. The patients received either 
Table 2 Results from the Phase III acute VTE studies with NOACs - subgroup of patients with PE (index event PE \pm DVT)

\begin{tabular}{|c|c|c|c|c|c|c|c|c|}
\hline & \multicolumn{2}{|c|}{ EINSTEIN PE ${ }^{21}$} & \multicolumn{2}{|c|}{ AMPLIFY ${ }^{22}$} & \multicolumn{2}{|c|}{ RE-COVER pooled ${ }^{24}$} & \multicolumn{2}{|c|}{ Hokusai-VTE ${ }^{25, a}$} \\
\hline & Rivaroxaban & $\begin{array}{l}\text { Enoxaparin/ } \\
\text { VKA }\end{array}$ & Apixaban & $\begin{array}{l}\text { Enoxaparin/ } \\
\text { warfarin }\end{array}$ & $\begin{array}{l}\text { Heparin/ } \\
\text { dabigatran }\end{array}$ & $\begin{array}{l}\text { Heparin/ } \\
\text { warfarin }\end{array}$ & $\begin{array}{l}\text { Heparin/ } \\
\text { edoxaban }\end{array}$ & $\begin{array}{l}\text { Heparin/ } \\
\text { warfarin }\end{array}$ \\
\hline \multicolumn{9}{|c|}{ Primary efficacy end point } \\
\hline Definition & \multicolumn{2}{|c|}{$\begin{array}{l}\text { Recurrent symptomatic VTE: } \\
\text { composite of fatal or nonfatal PE } \\
\text { or DVT }\end{array}$} & \multicolumn{2}{|c|}{$\begin{array}{l}\text { First recurrent } \\
\text { symptomatic VTE or } \\
\text { VTE-related death }\end{array}$} & \multicolumn{2}{|c|}{$\begin{array}{l}\text { Recurrent symptomatic } \\
\text { objectively confirmed VTE } \\
\text { and related death }\end{array}$} & \multicolumn{2}{|c|}{$\begin{array}{l}\text { Recurrent symptomatic VTE: } \\
\text { composite of DVT or nonfatal } \\
\text { or fatal PE }\end{array}$} \\
\hline $\mathrm{n} / \mathrm{N}(\%)$ & $50 / 2,419(2.1)$ & $44 / 2,413(1.8)$ & $2 \mathrm{I} / 900(2.3)$ & $23 / 886(2.6)$ & I8/795 (2.3) & $21 / 807(2.6)$ & $47 / 1,650(2.8)$ & $65 / 1,669(3.9)$ \\
\hline HR or RR $(95 \% \mathrm{Cl})$ & \multicolumn{2}{|c|}{ HR I.I2 (0.75-I.68) } & \multicolumn{2}{|c|}{ RR $0.90(0.50-1.6 I)$} & \multicolumn{2}{|l|}{ NR } & \multicolumn{2}{|c|}{ HR $0.73(0.50-1.06)$} \\
\hline \multicolumn{9}{|l|}{ Major bleeding } \\
\hline $\mathrm{n} / \mathrm{N}(\%)$ & $26 / 2,412(I .1)$ & $52 / 2,405(2.2)$ & $4 / 928(0.4)$ & $25 / 902(2.8)$ & NR & NR & NR & NR \\
\hline $\mathrm{HR}(95 \% \mathrm{Cl})$ & $0.49(0.31-0.79)$ & & NR & & NR & & NR & \\
\hline \multicolumn{9}{|c|}{ Major or clinically relevant nonmajor bleeding } \\
\hline $\mathrm{n} / \mathrm{N}(\%)$ & $249 / 2,412(10.3)$ & $274 / 2,405(11.4)$ & NR & NR & NR & NR & NR & NR \\
\hline HR (95\% Cl) & $0.90(0.76-1.07)$ & & NR & & NR & & NR & \\
\hline
\end{tabular}

Note: aodified intention-to-treat and safety analyses.

Abbreviations: $\mathrm{Cl}$, confidence interval; DVT, deep vein thrombosis; HR, hazard ratio; NOAC, nonvitamin K antagonist oral anticoagulant; NR, not reported; PE, pulmonary embolism; RR, relative risk; VKA, vitamin $\mathrm{K}$ antagonist; VTE, venous thromboembolism.

rivaroxaban or enoxaparin/VKA therapy. ${ }^{21}$ Rivaroxaban was noninferior to enoxaparin/VKA for the primary efficacy end point, defined as symptomatic recurrent VTE $(2.1 \%$ vs $1.8 \%$; hazard ratio [HR] 1.12; 95\% CI 0.75-1.68; Table 2 ). Although the rates of major and nonmajor clinically relevant bleeding events (principal safety outcome) were similar in both treatment arms $(10.3 \%$ vs $11.4 \%$; HR 0.90 ; 95\% CI 0.76-1.07; $P=0.23$ ), the rates of major bleeding were significantly lower with rivaroxaban compared with enoxaparin/VKA ( $1.1 \%$ vs $2.2 \%$; HR 0.49 ; $95 \%$ CI $0.31-$ $0.79 ; P=0.003)$. Importantly, rivaroxaban was also associated with lower rates of intracranial hemorrhage. ${ }^{21}$

Unlike the EINSTEIN trials, the Phase III studies of other NOACs (apixaban, dabigatran, and edoxaban) have enrolled mixed populations of DVT and PE patients when assessing these agents for the treatment of acute VTE. ${ }^{22-25}$ Nevertheless, studies with apixaban and edoxaban have published efficacy and safety outcomes of PE-only populations, and a pooled analysis of the dabigatran studies has published efficacy outcomes for the PE populations included in the respective trials (Table 2). ${ }^{22,24,25}$ Monotherapy with apixaban was noninferior to enoxaparin/ warfarin for the primary efficacy end point, defined as the composite of recurrent symptomatic VTE and VTE-related death $(2.3 \%$ vs $2.6 \%$; HR $0.9 ; 95 \%$ CI $0.5-1.61$; Table 2$) .{ }^{22}$ The rates of major bleeding (principal safety outcome) were significantly lower in the apixaban group compared with the enoxaparin/warfarin group ( $0.4 \%$ vs $2.8 \%$; no HR or $95 \%$ CI given; Table 2). In the dual-drug Hokusai-VTE study, edoxaban was noninferior to warfarin for the prevention of recurrent symptomatic VTE (primary efficacy end point; $2.8 \%$ vs $3.9 \%$; HR 0.73 ; $95 \%$ CI $0.50-1.06$ ) (Table 2). ${ }^{25}$ The rates of major plus clinically relevant nonmajor bleeding (principal safety outcome) were similar in both treatment arms (10.1\% vs $11.2 \%$; no HR or $95 \%$ CI given). Furthermore, in a pooled analysis of the dabigatran trials, the rates of recurrent symptomatic VTE and VTE-related death (primary efficacy outcome) in patients with symptomatic PE were similar in the dabigatran and warfarin treatment groups (2.3\% vs $2.6 \%$; no HR or $95 \%$ CI given). ${ }^{24}$ No safety outcomes were reported for the PE population in this study.

The Phase III trials with the NOACs differ with regard to many aspects of study design, including once-daily or twice-daily oral dosing, initial parenteral anticoagulation, and differences in exclusion and inclusion criteria (Table 3). In short, rivaroxaban and edoxaban were given once daily (after an initial 21-day period of twice-daily dosing in the case of rivaroxaban), whereas apixaban and dabigatran were given twice daily. ${ }^{21-25,44}$ The Phase III studies with rivaroxaban and apixaban used single-drug therapy, whereas dabigatran and edoxaban followed a dual-drug approach with initial anticoagulation with heparins before initiation of the study drug. An open-label study design was utilized for rivaroxaban, whereas a double-blind design was employed for apixaban, dabigatran, and edoxaban..$^{21-25,44}$ The treatment duration was 3 months, 6 months, or 12 months with rivaroxaban, ${ }^{21,44} 6$ months with apixaban ${ }^{22}$ and dabigatran, ${ }^{23,24}$ and 3-12 months with edoxaban. ${ }^{25}$ The proportion of patients with unprovoked VTE was also different across the studies. In the AMPLIFY study, $89.8 \%$ of patients presented with unprovoked VTE, whereas this group accounted for 
Table 3 Key features of study designs of the Phase III VTE treatment studies with NOACs

\begin{tabular}{|c|c|c|c|c|}
\hline & EINSTEIN pooled ${ }^{46 a}$ & AMPLIFY'22 & RE-COVER pooled ${ }^{24}$ & Hokusai-VTE ${ }^{25}$ \\
\hline Randomized patients, $n$ & 8,282 & 5,395 & 5,107 & 8,292 \\
\hline Drugs compared & $\begin{array}{l}\text { Rivaroxaban vs enoxaparin/ } \\
\text { VKA }\end{array}$ & $\begin{array}{l}\text { Apixaban vs enoxaparin/ } \\
\text { warfarin }\end{array}$ & $\begin{array}{l}\text { Heparin/dabigatran vs heparin/ } \\
\text { warfarin }\end{array}$ & $\begin{array}{l}\text { Heparin/edoxaban vs } \\
\text { heparin/warfarin }\end{array}$ \\
\hline Study design & Open label, assessor blind & Double blind & Double blind & Double blind \\
\hline Statistical outcome & Noninferiority & Noninferiority & Noninferiority & Noninferiority \\
\hline $\begin{array}{l}\text { Treatment regimen for } \\
\text { NOAC }\end{array}$ & $\begin{array}{l}15 \mathrm{mg} \text { bid for } 21 \text { days } \\
\text { followed by } 20 \mathrm{mg} \text { od }\end{array}$ & $\begin{array}{l}10 \mathrm{mg} \text { bid for } 7 \text { days } \\
\text { followed by } 5 \mathrm{mg} \text { bid }\end{array}$ & $150 \mathrm{mg}$ bid & $60 \mathrm{mg}$ od $(2 \times 30 \mathrm{mg} \text { tablets })^{\mathrm{b}}$ \\
\hline $\begin{array}{l}\text { Treatment duration } \\
\text { (months) }\end{array}$ & 3,6, or 12 & 6 & 6 & $3-12$ \\
\hline
\end{tabular}

Notes: aEINSTEIN DVT and EINSTEIN PE had the same study design. ${ }^{\circ}$ Denotes a reduced dose given to patients with $\mathrm{CrCl} 30-50 \mathrm{~mL} / \mathrm{min}$ or body weight $<60 \mathrm{~kg}$ or receiving concomitant treatment with a potent P-glycoprotein inhibitor.

Abbreviations: bid, twice daily; $\mathrm{CrCl}$, creatinine clearance; DVT, deep vein thrombosis; NOAC, nonvitamin $\mathrm{K}$ antagonist oral anticoagulant; od, once daily; PE, pulmonary embolism; VKA, vitamin $\mathrm{K}$ antagonist; VTE, venous thromboembolism.

only $62.0 \%, 64.5 \%$, and $65.7 \%$ of patients in EINSTEIN DVT, EINSTEIN PE, and Hokusai-VTE studies, respectively. ${ }^{21,22,25,44}$ In the pooled analysis of RE-COVER and RE-COVER II, $35.6 \%$ of all patients had an unprovoked episode. ${ }^{24}$ Ultimately, these differences between the studies of NOACs prevent accurate head-to head comparisons of outcomes. The most suitable NOAC for each patient should be selected individually by considering the clinical profile of the patient, the pharmacological profile, and contraindications of the NOAC (Table 1) and patient preference.

\section{Discussion}

Economic and infrastructural pressures on hospitals often disproportionately affect the ED, and excessive lengths of hospital stay for patients admitted through the ED, some of whom could have their care safely delivered in the community, increase this pressure further. Increasingly, EDs are being asked to identify opportunities to reduce admission rates without compromising the delivery of safe and effective health care.

In the ED setting, physicians are familiar and comfortable with prescribing traditional parenteral anticoagulants for the treatment of acute DVT or PE. For many years, the standard therapy has been weight-adjusted dosing with parenteral heparin overlapping with and followed by an oral VKA. ${ }^{5,7}$ A critical threshold of high-quality evidence for treating PE with NOACs has been established in recent years. ${ }^{21-25}$ Rivaroxaban, apixaban, dabigatran, and edoxaban offer alternative treatment options for PE and have many well-described advantages over conventional therapies. Convenient administration and a fixed daily dosing regimen, in particular, can simplify patient management and may render outpatient treatment more practical. ${ }^{11}$ Rivaroxaban and apixaban may be particularly suitable candidates for early discharge and outpatient treatment owing to their single-drug-based therapeutic approach, for which no bridging is necessary between acute and longer term treatment.

Despite the advantages of NOAC-based anticoagulant therapy, adoption of NOACs has remained slow for DVT/PE treatment and prevention. Different reasons for a slow transition have been outlined in the treatment of nonvalvular atrial fibrillation and are likely to be applicable to other indications. The main reasons include cost-benefit issues and a perceived failure to live up to the expected ease of use. ${ }^{45}$ Despite some evidence of a long-term financial advantage of NOAC therapy, the initial cost difference between NOACs and warfarin (ie, a few euros vs a few cents per day) seems to influence choice at the prescribing level. Although ease of use is often advocated, important classes of drugs interfere with NOACs via interaction with cytochrome P450 3A4 and P-glycoprotein, including drugs used in cardiology (verapamil) and HIV treatment (ritonavir). ${ }^{17-20}$ NOACs are contraindicated/not recommended for pregnant women and for the pediatric population, owing to the lack of relevant clinical data. Dose reduction for elderly patients without comorbidities is recommended for dabigatran but not for other NOACs. ${ }^{17-20}$ Finally, the lack of reversal agents, together with missing experience in dealing with overdoses or impaired excretion, adds to the reluctance to switch to a NOAC. ${ }^{45}$

Understandably, choice of anticoagulant is a difficult decision for health care professionals: do you stand by the 'better the devil you know' maxim and opt for conventional therapy, or choose the new drug that sounds promising but might bring different drawbacks from those linked to conventional treatment?. In some cases, including the PE case study presented earlier, the prospect of a simple, noninvasive, home-based treatment that might enable early discharge makes NOACbased therapy appealing. In this case study, a patient with a low-risk PE is taking care of a disabled family member; therefore, the initial cost associated with the NOAC may be 
compensated for by both early discharge and a reduced burden on health care resources (both by the patient and potentially by the mother if she was left without care). Drug-drug interactions do not seem to be relevant in this case, and the risk of developing a major bleeding event is insignificant. Because NOACs have a relatively short half-life, there is no pressing need for antidotes, and alternative means of treatment are available in the unlikely event of life-threatening bleeding. Thus, a large proportion of patients with low-risk PE now have a new treatment option that suits their lifestyle and domestic responsibilities. The lives of patients undergoing treatment for PE no longer need to be dictated by treatment regimens. A new alternative embracing suitability, education, and arrangements for continuity of care can be delivered in a short time frame in the ED setting, facilitating earlier discharge.

In the century of personalized medicine, the choice of optimal treatment is one in which patient phenotype and medical history represent a significant part of the decisionmaking process. Careful assessment of all available treatment options is key for advancing medical practices and enhancing performance of the public health system.

\section{Acknowledgment}

The author would like to acknowledge Gem Auddy, who provided editorial support with funding from Bayer HealthCare Pharmaceuticals and Janssen Scientific Affairs, LLC.

\section{Disclosure}

$\mathrm{J}$ Ryan has received consulting honoraria from Bayer Pharma AG and Boehringer Ingelheim. The author reports no other conflicts of interest in this work.

\section{References}

1. Douma RA, Kamphuisen PW, Büller HR. Acute pulmonary embolism. Part 1: epidemiology and diagnosis. Nat Rev Cardiol. 2010;7(10): 585-596.

2. Stein PD, Kayali F, Olson RE. Estimated case fatality rate of pulmonary embolism, 1979 to 1998. Am J Cardiol. 2004;93(9):1197-1199.

3. Girard P, Musset D, Parent F, Maitre S, Phlippoteau C, Simonneau G. High prevalence of detectable deep venous thrombosis in patients with acute pulmonary embolism. Chest. 1999;116(4):903-908.

4. Moser KM, Fedullo PF, LittleJohn JK, Crawford R. Frequent asymptomatic pulmonary embolism in patients with deep venous thrombosis. JAMA. 1994;271(3):223-225.

5. Rudd KM, Phillips EL. New oral anticoagulants in the treatment of pulmonary embolism: efficacy, bleeding risk, and monitoring. Thrombosis. 2013;2013:973710.

6. Goldstein P, Elalamy I, Huber K, Danchin N, Wiel E. Rivaroxaban and other non-vitamin $\mathrm{K}$ antagonist oral anticoagulants in the emergency treatment of thromboembolism. Int J Emerg Med. 2013;6(1):25.

7. Agnelli G, Becattini C, Franco L. New oral anticoagulants for the treatment of venous thromboembolism. Best Pract Res Clin Haematol. 2013;26(2):151-161.
8. Kearon C, Akl EA, Ornelas J, et al. Antithrombotic therapy for VTE disease: CHEST guideline and expert panel report. Chest. 2016;149(2):315-352.

9. Turpie AGG, Fisher WD, Bauer KA, et al. BAY 59-7939: an oral, direct Factor Xa inhibitor for the prevention of venous thromboembolism in patients after total knee replacement. A phase II dose-ranging study. J Thromb Haemost. 2005;3(11):2479-2486.

10. Hoffman R, Brenner B. The promise of novel direct oral anticoagulants. Best Pract Res Clin Haematol. 2012;25(3):351-360.

11. Mueck W, Schwers S, Stampfuss J. Rivaroxaban and other novel oral anticoagulants: pharmacokinetics in healthy subjects, specific patient populations and relevance of coagulation monitoring. Thromb J. 2013;11(1):10.

12. Konstantinides SV, Torbicki A, Agnelli G, et al. 2014 ESC Guidelines on the diagnosis and management of acute pulmonary embolism. Eur Heart J. 2014;35(43):3033-3069.

13. National Institute for Health and Care Excellence [webpage on the Internet]. Rivaroxaban for Treating Pulmonary Embolism and Preventing Recurrent Venous Thromboembolism; NICE Technology Appraisal Guidance 287. 2013. Available from: http://www.nice.org.uk/guidance/ TA287. Accessed September 14, 2015.

14. National Institute for Health and Care Excellence [webpage on the Internet]. Apixaban for the Treatment and Secondary Prevention of Deep Vein Thrombosis and/or Pulmonary Embolism; NICE Technology Appraisal Guidance TA341. 2015. Available from: http://www.nice.org. uk/guidance/ta341. Accessed September 14, 2015.

15. National Institute for Health and Care Excellence [webpage on the Internet]. Dabigatran Etexilate for the Treatment and Secondary Prevention of Deep Vein Thrombosis and/or Pulmonary Embolism; NICE Technology Appraisal Guidance TA327. 2014. Available from: http:// www.nice.org.uk/guidance/ta327. Accessed September 14, 2015.

16. National Institute for Health and Care Excellence [webpage on the Internet]. Edoxaban for Treating and for Preventing Deep Vein Thrombosis and Pulmonary Embolism; NICE Technology Appraisal Guidance TA354. 2015. Available from: http://www.nice.org.uk/guidance/ta354. Accessed September 14, 2015.

17. Bristol-Myers Squibb, Pfizer [webpage on the Internet]. Eliquis $®$ (apixaban) Summary of Product Characteristics. 2016. Available from: http:// www.ema.europa.eu/docs/en_GB/document_library/EPAR_-_Product_Information/human/002148/WC500107728.pdf. Accessed March 21, 2016.

18. Bayer Pharma AG [webpage on the Internet]. Xarelto (rivaroxaban) Summary of Product Characteristics. 2015. Available from: http://www. ema.europa.eu/docs/en_GB/document_library/EPAR_-_Product_Information/human/000944/WC500057108.pdf. Accessed March 21, 2016.

19. Boehringer Ingelheim International $\mathrm{GmbH}$ [webpage on the Internet]. Pradaxa ${ }^{\circledR}$ (dabigatran etexilate) Summary of Product Characteristics. 2016. Available from: http://www.ema.europa.eu/docs/en_GB/ document_library/EPAR_-_Product_Information/human/000829/ WC500041059.pdf. Accessed March 21, 2016.

20. Daiichi Sankyo Europe $\mathrm{GmbH}$ [webpage on the Internet]. Lixiana ${ }^{\circledR}$ (edoxaban) Summary of Product Characteristics. 2015. Available from: http://www.ema.europa.eu/docs/en_GB/document_library/ EPAR_-_Product_Information/human/002629/WC500189045.pdf. Accessed March 21, 2016.

21. The EINSTEIN-PE Investigators; Büller HR, Prins MH, et al. Oral rivaroxaban for the treatment of symptomatic pulmonary embolism. $N$ Engl J Med. 2012;366(14):1287-1297.

22. Agnelli G, Buller HR, Cohen A, et al. Oral apixaban for the treatment of acute venous thromboembolism. N Engl J Med. 2013;369(9):799-808.

23. Schulman S, Kearon C, Kakkar AK, et al. Dabigatran versus warfarin in the treatment of acute venous thromboembolism. $N$ Engl J Med. 2009;361(24):2342-2352.

24. Schulman S, Kakkar AK, Goldhaber SZ, et al. Treatment of acute venous thromboembolism with dabigatran or warfarin and pooled analysis. Circulation. 2014;129(7):764-772. 
25. The Hokusai-VTE Investigators; Büller HR, Décousus H, et al. Edoxaban versus warfarin for the treatment of symptomatic venous thromboembolism. N Engl J Med. 2013;369(15):1406-1415.

26. Aujesky D, Obrosky DS, Stone RA, et al. Derivation and validation of a prognostic model for pulmonary embolism. Am J Respir Crit Care Med. 2005;172(8):1041-1046.

27. Jiménez D, Aujesky D, Moores L, et al. Simplification of the Pulmonary Embolism Severity Index for prognostication in patients with acute symptomatic pulmonary embolism. Arch Intern Med. 2010;170(15): 1383-1389.

28. Fermann GJ, Erkens PM, Prins MH, Wells PS, Pap ÁF, Lensing AW. Treatment of pulmonary embolism with rivaroxaban: outcomes by simplified Pulmonary Embolism Severity Index score from a post hoc analysis of the EINSTEIN PE study. Acad Emerg Med. 2015;22(3):299-307.

29. Bamber L, Wang MY, Prins MH, et al. Patient-reported treatment satisfaction with oral rivaroxaban versus standard therapy in the treatment of acute symptomatic deep-vein thrombosis. Thromb Haemost. 2013;110(4):732-741.

30. Prins MH, Bamber L, Cano SJ, et al. Patient-reported treatment satisfaction with oral rivaroxaban versus standard therapy in the treatment of pulmonary embolism; results from the EINSTEIN PE trial. Thromb Res. 2015;135(2):281-288.

31. van Bellen B, Bamber L, Correa de Carvalho F, Prins M, Wang M, Lensing AW. Reduction in the length of stay with rivaroxaban as a single-drug regimen for the treatment of deep vein thrombosis and pulmonary embolism. Curr Med Res Opin. 2014;30(5):829-837.

32. Monagle P, Chan AK, Goldenberg NA, et al. Antithrombotic therapy in neonates and children: antithrombotic therapy and prevention of thrombosis, 9th ed: American College of Chest Physicians evidence-based clinical practice guidelines. Chest. 2012;141(2 suppl):e737S-e801S.

33. Prins MH, Lensing AWA, Brighton TA, et al. Oral rivaroxaban versus enoxaparin with vitamin $\mathrm{K}$ antagonist for the treatment of symptomatic venous thromboembolism in patients with cancer (EINSTEIN-DVT and EINSTEIN-PE): a pooled subgroup analysis of two randomised controlled trials. Lancet Haematol. 2014;1(1):e37-e46.

34. Siegal DM, Crowther MA. Acute management of bleeding in patients on novel oral anticoagulants. Eur Heart J. 2013;34(7):489b-498b.
35. Makris M, Van Veen JJ, Tait C, et al. Guideline on the management of bleeding in patients on antithrombotic agents. Br J Haematol. 2012;160(1):35-46.

36. Crowther M, Crowther MA. Antidotes for novel oral anticoagulants: current status and future potential. Arterioscler Thromb Vasc Biol. 2015;35(8):1736-1745.

37. Schiele F, van Ryn J, Canada K, et al. A specific antidote for dabigatran: functional and structural characterization. Blood. 2013;121(18):3554-3562.

38. Crowther M, Mathur A, Kitt M, et al. A phase 2 randomized, double-blind, placebo-controlled trial demonstrating reversal of rivaroxaban-induced anticoagulation in healthy subjects by andexanet alfa (PRT064445), an antidote for FXa inhibitors. Blood. 2013;122. Abstract 3636.

39. Beyer-Westendorf J, Förster K, Pannach S, et al. Rates, management, and outcome of rivaroxaban bleeding in daily care: results from the Dresden NOAC Registry. Blood. 2014;124(6):955-962.

40. Ageno W, Mantovani LG, Haas S, et al. XALIA: rationale and design of a non-interventional study of rivaroxaban compared with standard therapy for initial and long-term anticoagulation in deep vein thrombosis. Thromb J. 2014;12:16.

41. Haas S, Bode C, Norrving B, Turpie AGG. Practical guidance for using rivaroxaban in patients with atrial fibrillation: balancing benefit and risk. Vasc Health Risk Manag. 2014;10:101-114.

42. Heidbuchel H, Verhamme P, Alings M, et al. Updated European Heart Rhythm Association Practical Guide on the use of non-vitamin K antagonist anticoagulants in patients with non-valvular atrial fibrillation. Europace. 2015;17(10):1467-1507.

43. Buller HR, Davidson BL, Decousus H, et al. Subcutaneous fondaparinux versus intravenous unfractionated heparin in the initial treatment of pulmonary embolism. N Engl J Med. 2003;349(18):1695-1702.

44. The EINSTEIN Investigators. Oral rivaroxaban for symptomatic venous thromboembolism. N Engl J Med. 2010;363(26):2499-2510.

45. Shurlock B. New oral anticoagulants for non-valvular atrial fibrillation: harder to handle than expected. Eur Heart J. 2014;35(28):1825-1836.

46. Prins MH, Lensing AWA, Bauersachs R, et al. Oral rivaroxaban versus standard therapy for the treatment of symptomatic venous thromboembolism: a pooled analysis of the EINSTEIN-DVT and PE randomized studies. Thromb J. 2013;11(1):21.
Open Access Emergency Medicine

\section{Publish your work in this journal}

The Open Access Emergency Medicine is an international, peerreviewed, open access journal publishing original research, reports, editorials, reviews and commentaries on all aspects of emergency medicine. The manuscript management system is completely online and includes a very quick and fair peer-review system, which is all

\section{Dovepress}

easy to use. Visit http://www.dovepress.com/testimonials.php to read real quotes from published authors. 